\title{
Unidirectional consolidation of clay soils and flocculated suspensions
}

\author{
Stephen S. L. Peppin
}

\begin{abstract}
A model of the unidirectional consolidation of a clay soil or flocculated suspension between a series of parallel drains is developed. A convective-diffusion equation for the pore pressure is derived, and an equal-strain approximation leads to an expression for the average effective stress profile between the drains. The solution depends on a Peclet number quantifying the ratio of the bulk soil flow rate to the rate of consolidation. By adjusting the number, height and spacing of the drains, very high rates of dewatering can be achieved. A potential application of the method to the rapid dewatering of mine tailings is described.
\end{abstract}

\section{Introduction}

More than one million tonnes of waste tailings are produced daily by global mining operations [1-3]. A tailings suspension is a multicomponent mixture of colloidal particles (clay + silt), a coarse fraction (silt + sand) and a suspending fluid (water + dissolved ions + residual oil) [4]. A major challenge of tailings treatment methods is the safe and economical removal of the fine clays from the suspension [5]. Currently the most widely used method is long-term sedimentation and self-weight consolidation [6]. However, owing to the very slow sedimentation rates of flocculated colloidal particles, this method involves storing the unprocessed tailings in large ponds for decades to centuries $[7,8]$. The tailings dams occasionally rupture, causing widespread environmental damage, and there is a need for faster, more economical methods.

An alternative dewatering method studied here is similar to what occurs in the intestines. The large intestine takes a multicomponent suspension of particulates, colloids, ions and oils and dewaters the mixture via a type of plug-flow consolidation $[9,10]$. The method is much faster than sedimentation or self-weight consolidation and requires relatively little expenditure of energy. In this work progress toward developing a quantitative model of a similar process on industrial scales is made by deriving equations governing unidirectional consolidation between two vertical porous surfaces. In Section 2 the conservation equations are first described, leading to a convective-diffusion equation for the pore pressure between the drains. In Section 3 an equal-strain approximation is employed to obtain analytical expressions for the steady-state pore pressure and effective stress profiles. Finally, Section 4 describes a potential large-scale application as a method to reduce the size of tailings ponds.

\section{Governing equations}

Figure 1 illustrates the system to be studied. A clay soil or flocculated colloidal suspension is slowly moving downward via plug flow between two porous vertical drains. As the mixture moves some of the pore fluid enters the drains and the soil consolidates. In the slow-compaction limit $[11,12]$ the porosity in the $x$-direction remains approximately constant. If the vertical flowrate is slow relative to the rate at which the pore pressure equilibrates horizontally, and if a near-slip boundary condition is maintained at the drains, a type of plug-flow consolidation will occur similar to the expression-filtration that occurs in the intestines $[9,10]$. Here an equation is obtained for the

For God so loved the world, that He gave His only begotten Son, that whosoever believeth in Him should not perish, but have everlasting life. For God sent not His Son into the world to condemn the world; but that the world through Him might be saved. John 3:16-17 


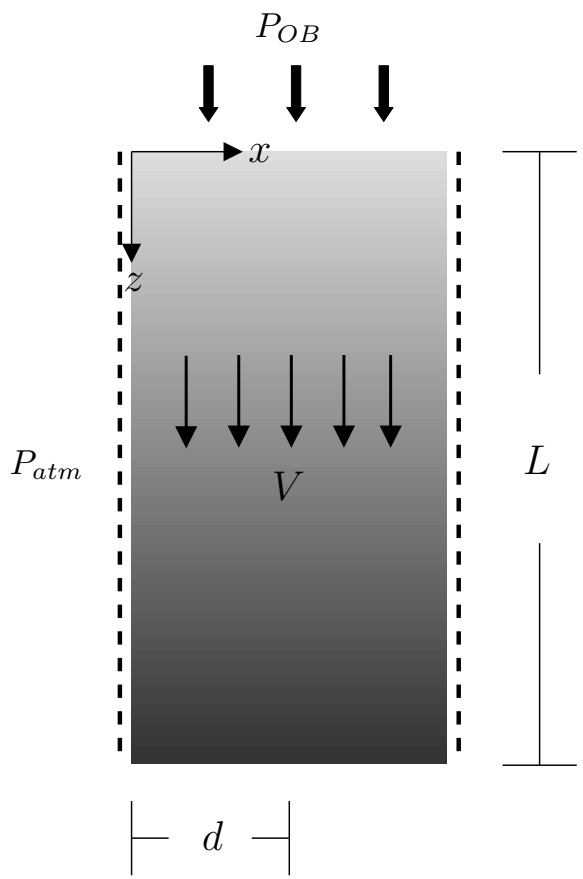

Figure 1: Schematic of the unidirectional consolidation of a clay soil between two vertical drains (dashed lines). The soil is moving downward via plug flow at speed $V$ under an overburden pressure $P_{O B}$. The pore pressure outside the drains is at atmospheric pressure $P_{a t m}<P_{O B}$. As water passes through the drains the soil consolidates. At steady state the total mass flux through the drains and out through the base of the system is equal to the input mass flux.

vertical effective stress profile between the drains. Assuming the fluid and solids are incompressible, conservation of mass of a volume element of the mixture is given by the equations

$$
\frac{\partial \phi}{\partial t}+\nabla \cdot \phi \boldsymbol{v}_{s}=0 \text { and } \boldsymbol{\nabla} \cdot \boldsymbol{v}=0
$$

where $\boldsymbol{v}=(1-\phi) \boldsymbol{v}_{f}+\phi \boldsymbol{v}_{s}$ is the volume average velocity, $\phi$ is the volume fraction occupied by the solid particles, $\boldsymbol{v}_{f}$ is the average velocity of the pore fluid and $\boldsymbol{v}_{s}$ is the average velocity of the solid particles $[13,14]$. Combining the identity $\boldsymbol{\nabla} \cdot \phi \boldsymbol{v}=\boldsymbol{v} \cdot \boldsymbol{\nabla} \phi+\phi \boldsymbol{\nabla} \cdot \boldsymbol{v}[15]$ with equation (1a) and using $(1 b)$ gives

$$
\frac{\partial \phi}{\partial t}+\boldsymbol{v} \cdot \nabla \phi=\nabla \cdot \phi \boldsymbol{q}
$$

where $\boldsymbol{q}=\boldsymbol{v}-\boldsymbol{v}_{s}=n\left(\boldsymbol{v}_{f}-\boldsymbol{v}_{s}\right)$ is the Darcy fluid flux.

Here gravitational effects are neglected in between the drains, and the only effect of gravity is to produce an overburden pressure $P_{O B}$ at $z=0$, as illustrated in figure 1. Darcy's law can then be written as

$$
\boldsymbol{q}=-\frac{k}{\mu} \nabla p,
$$

where $k$ is the permeability and $\mu$ is the fluid viscosity. Making the constitutive assumption $p=p(T, P, \phi)$, where $T$ and $P$ are the temperature and mixture pressure, assumed constant, differentiating $p$ gives

$$
\mathrm{d} p=\left(\frac{\partial p}{\partial \phi}\right)_{T, P} \mathrm{~d} \phi=-\frac{\kappa_{p}}{\phi} \mathrm{d} \phi,
$$

where $\kappa_{p}=-\phi(\partial p / \partial \phi)_{T, P}=\phi\left(\partial \sigma^{\prime} / \partial \phi\right)_{T, P}$ is the bulk modulus of the porous matrix and $\sigma^{\prime}=P-p$ is the effective stress $[14,16]$. Combining (4) and (3) with (2) and assuming $\phi k / \mu$ is constant leads to a convection-diffusion equation for the pressure

$$
\frac{\partial p}{\partial t}+\boldsymbol{v} \cdot \nabla p=C_{v} \boldsymbol{\nabla} \cdot \boldsymbol{\nabla} p
$$


where $C_{v}=k \kappa_{p} / \mu$ is the consolidation coefficient $[16,17]$.

\section{Approximate solution}

By making an equal-strain approximation $[17,18]$ an analytical solution to (5) can be obtained. In this approach equation (5) is written in the approximate form

$$
\frac{\partial \bar{p}}{\partial t}+V \frac{\partial \bar{p}}{\partial z}=C_{v} \frac{\partial^{2} p}{\partial x^{2}}
$$

where

$$
\bar{p}(z, t)=\frac{1}{d} \int_{0}^{d} p(x, z, t) \mathrm{d} x
$$

is the average pore pressure between the drain boundary $x=0$ and the centreline $x=d$, and $V$ is the average vertical velocity of the mixture.

Equation (6) assumes that Darcy flow occurs mainly in the $x$-direction, and that the volume of pore fluid passing horizontally through the drain boundaries is balanced by consolidation of the mixture, averaged over the horizontal cross-section [17]. Also, it is assumed there is a slip boundary condition at the drain surface leading to plug flow, so that $\boldsymbol{v}=V \hat{z}$. This condition can be approximated either via collapsible drain boundaries, as in the deformable plastic drains used in soils [19]; or via a thin lubricating layer at the drain boundary as occurs in the intestines [9, 10]. Assuming the fluid in the drains is at atmospheric pressure and that the pore pressure is symmetric about the centreline $x=d$, the boundary conditions on $p$ are

$$
p=P_{a t m} \quad(x=0), \quad \text { and } \quad \frac{\partial p}{\partial x}=0 \quad(x=d) .
$$

The boundary and initial conditions on the horizontally-averaged pore pressure $\bar{p}$ are

$$
\bar{p}=p_{0} \quad(z=0) \quad \text { and } \quad \bar{p}=p_{0} \quad(t=0),
$$

where $p_{0}=P-\sigma_{0}^{\prime}$ is the intial pore pressure in the mixture, $P=P_{a t m}+P_{O B}$ is the total pressure acting on the system and $\sigma_{0}^{\prime}$ is the initial effective stress supported by the particle matrix within the mixture.

Before integrating (6) it is convenient to write the equations in dimensionless form. Inserting the scalings

$$
x^{*}=x / d, \quad z^{*}=z / L, \quad p^{*}=\left(p-P_{a t m}\right) /\left(p_{0}-P_{a t m}\right), \quad t^{*}=t C_{v} / d^{2}
$$

into (6) and (7) leads to

$$
\frac{\partial \bar{p}^{*}}{\partial t^{*}}+P e \frac{\partial \bar{p}^{*}}{\partial z^{*}}=\frac{\partial^{2} p^{*}}{\partial x^{* 2}}
$$

and

$$
\bar{p}^{*}=\int_{0}^{1} p^{*} \mathrm{~d} x^{*},
$$

where $P e=d^{2} V /\left(L C_{v}\right)$ is a Peclet number characterizing the ratio of the bulk suspension flow rate $V$ to the rate of consolidation $L C_{v} / d^{2}$. When $P e \gg 1$ little consolidation occurs, while when $P e \ll 1$ there is little bulk convection and the equations reduce to Hansbo's model [17,18]. With the scalings (10) the boundary conditions (8) and (9) become

$$
p^{*}=0 \quad\left(x^{*}=0\right), \quad \frac{\partial p^{*}}{\partial x^{*}}=0 \quad\left(x^{*}=1\right),
$$

and

$$
\bar{p}^{*}=1 \quad\left(z^{*}=0\right), \quad \bar{p}^{*}=1 \quad\left(t^{*}=0\right) .
$$


(a)

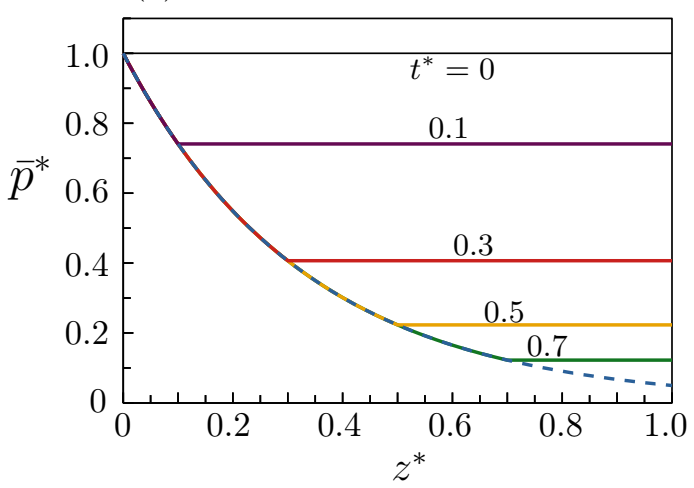

(b)

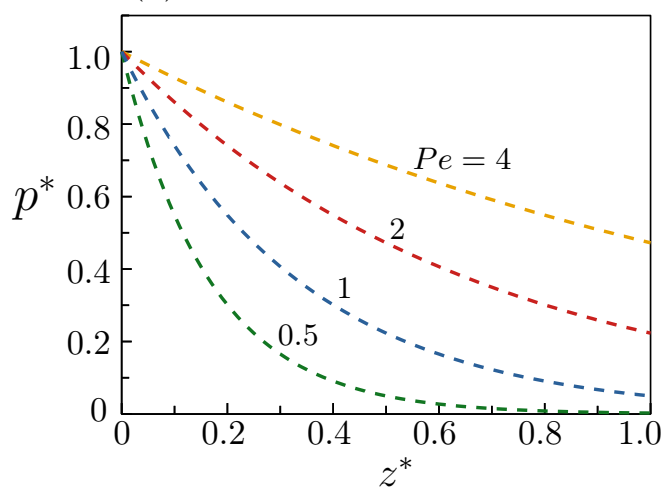

Figure 2: (a) Pore pressure profiles during unidirectional consolidation. The solid curves are the solution to (17) at several different times for the case $P e=1$. The dashed curve is the steady-state solution (19). (b) Steady-state pore pressure profiles at several different Peclet numbers.

Integrating (11) with respect to $x^{*}$, bearing in mind that $\bar{p}^{*}$ is independent of $x^{*}$, and using the boundary condition $(13 b)$ leads to

$$
\frac{\partial p^{*}}{\partial x^{*}}=\left(x^{*}-1\right)\left(\frac{\partial \bar{p}^{*}}{\partial t^{*}}+P e \frac{\partial \bar{p}^{*}}{\partial z^{*}}\right) .
$$

Integrating again using the boundary condition $(13 a)$ leads to

$$
p^{*}=x^{*}\left(\frac{1}{2} x^{*}-1\right)\left(\frac{\partial \bar{p}^{*}}{\partial t^{*}}+P e \frac{\partial \bar{p}^{*}}{\partial z^{*}}\right) .
$$

Inserting (16) into (12) then gives a linear first-order PDE for the average pore pressure

$$
\frac{\partial \bar{p}^{*}}{\partial t^{*}}+P e \frac{\partial \bar{p}^{*}}{\partial z^{*}}+3 \bar{p}^{*}=0 .
$$

With the boundary and initial conditions given by (14), equation (17) has the solution

$$
\bar{p}^{*}\left(z^{*}, t^{*}\right)=\left\{\begin{array}{lc}
\mathrm{e}^{-3 z^{*} / P e} & \left(z^{*} \leq P e t^{*}\right), \\
\mathrm{e}^{-3 t^{*}} & \left(z^{*}>\text { Pet } t^{*}\right) .
\end{array} .\right.
$$

Figure $2 a$ shows the solution (18) plotted versus $z^{*}$ at various $t^{*}$ (solid curves) along with the steady-state $\left(t^{*} \rightarrow \infty\right)$ solution

$$
\bar{p}^{*}=\mathrm{e}^{-3 z^{*} / P e},
$$

shown as the dashed curve. Figure $(2 b)$ shows the steady-state solution for various values of the Peclet number $P e$. In the large Peclet number limit $P e \gg 1$ the soil moves quickly through the system and the pressure profile is linear, $\bar{p}^{*}=1-3 z^{*} / P e$. When $P e=0$ the soil consolidates uniformly and there is no steady-state; the time-dependent consolidation process is then given by Hansbo's solution $\bar{p}^{*}=\mathrm{e}^{-3 t^{*}}[17,18]$.

In terms of dimensional quantities equation (19) becomes

$$
\bar{p}=P_{a t m}+\left(P_{O B}-\sigma_{0}^{\prime}\right) \mathrm{e}^{-\frac{3 C_{v}}{d^{2} V} z} .
$$

and the steady-state effective stress distribution can be obtained as $\sigma^{\prime}=P-\bar{p}$ or

$$
\sigma^{\prime}=P_{O B}-\left(P_{O B}-\sigma_{0}^{\prime}\right) \mathrm{e}^{-\frac{3 C_{v}}{d^{2} V}} .
$$

Equation (21) shows that the effective stress on the soil matrix increases with $z$ from its initial value $\sigma_{0}^{\prime}$ at $z=0$. As an example, for a clay slurry with initial effective stress $\sigma_{0}^{\prime}=0.1 \mathrm{kPa}$, consolidation coefficient $C_{v}=10^{-8} \mathrm{~m}^{2} / \mathrm{s}$, overburden pressure $P_{O B}=700 \mathrm{kPa}$, drain spacing $d=0.1 \mathrm{~m}$ and mixture velocity $V=0.01 \mathrm{~m} / \mathrm{s}$, equation (21) gives $z=\left(d^{2} V /\left(3 C_{v}\right) \ln \left[\left(P_{O B}-\sigma_{0}^{\prime}\right) /\left(P_{O B}-\sigma^{\prime}\right)\right]=23 \mathrm{~m}\right.$ as the drain height required to consolidate the soil to an effective stress of $\sigma^{\prime}=5 \mathrm{kPa}$. 


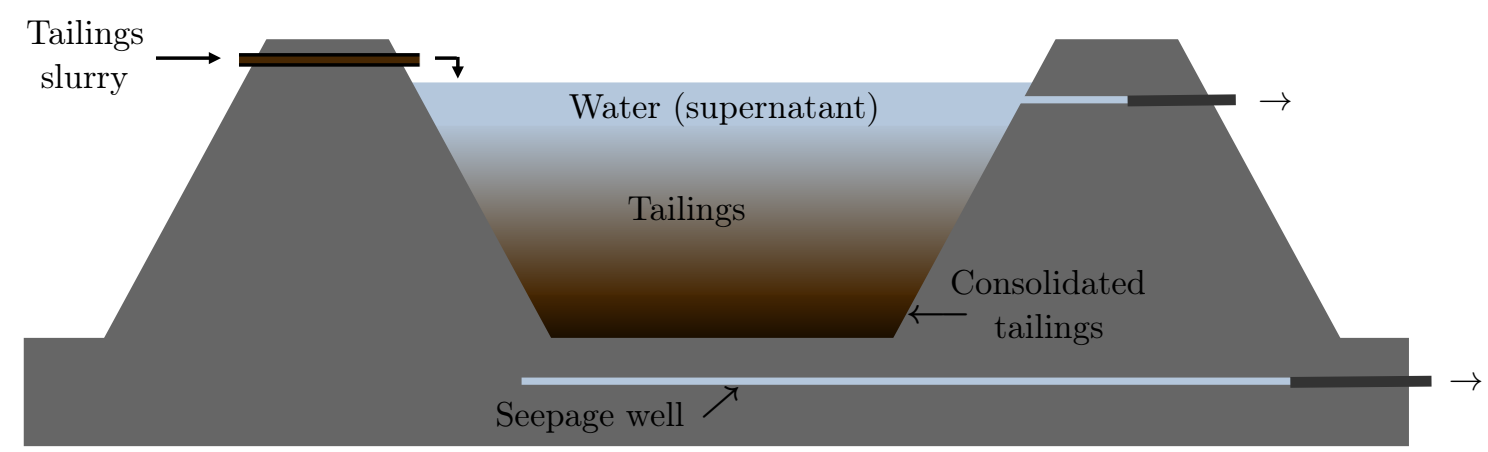

Figure 3: Schematic of a tailings pond for batch storage of mine tailings. Because of the very slow sedimentation and self-weight consolidation rate of colloidal particles, the estimated reclamation time is several centuries [7,8], and the pond steadily increases in volume during the lifetime of the mine. The pond base acts like a drain, allowing some of the water to pass through into the seepage well while retaining the clay and solid particles [20]. If the consolidated clay at the base could be continuously removed the efficiency of the consolidation process would be enhanced (figure 4).

\section{Application to mine tailings}

Currently most tailings ponds operate in a batch consolidation mode, as illustrated in figure 3, with estimated reclamation times from decades up to several hundred years $[7,8]$. The long time is related to the necessity of the tailings to consolidate to a minimum shear strength such that the clay can be used in land reclamation efforts [6,8]. A significant issue with current pond designs, is that the components of the slurry segregate as the slurry flows down the beach area of the pond, with the larger particles sedimenting out and only the colloidal-sized particles reaching the pond. These colloidal particles then take many decades to sediment to a water content low enough for land reclamation. One method that has been used to enhance the rate of consolidation is to install vertical wick drains in the top of the pond [21]. While this method works well, it is expensive and labour-intensive, the drains tend to deform over time [19], and the method does not eliminate the need for the tailings pond itself. Furthermore, the efficiency of the drains depends on a sufficient overburden pressure, which is smallest at the surface of the pond. If the drains could be installed at the base of the pond where the overburden is largest, the rate of consolidation would be enhanced.

In this section an alternative continuous-flow tailings pond design is described. The system involves steady-state consolidation between a series of vertical drains installed at the base of the pond or within a consolidation tower prior to mining operations (figure 4). The equal-strain consolidation model gives an equation for the effective stress at the base of the system as a function of the tailings production rate and pond/tower dimensions. The continuous-flow mode greatly increases the rate of consolidation, reducing the need for long-term tailings storage.

\subsection{Concept and Unit Operations}

A schematic of the continuous-flow tailings pond/consolidation-tower is shown in figure 4 . At the base of the pond are a series of vertical drains of height $L$ and spacing $2 d$. The tailings slurry is poured into the system at rate $V$ to height $H$, and at steady state the consolidated tailings are removed at the same rate from the base. The pond/tower height provides an overburden pressure $P_{O B}=\rho g H$ that drives consolidation between the drains.

The steady-state consolidation model (Section 3) gives the following equation for the effective 


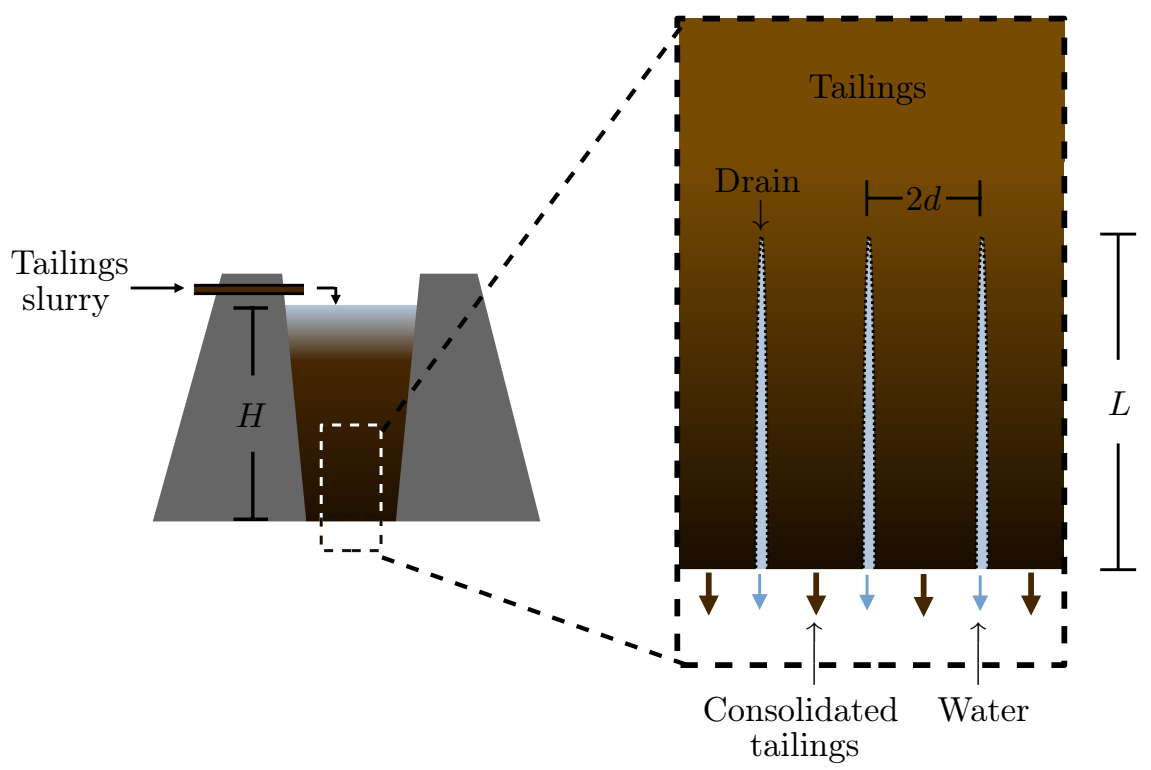

Figure 4: Schematic of a unidirectional consolidation tailings pond/tower for continuous-flow dewatering of mine tailings. Horizontal consolidation occurs between the vertical drains. At steady state the total mass flux of water and consolidated tailings out through the base of the system is equal to the input slurry flux, eliminating the need for long-term storage.

stress $\sigma^{\prime}$ at the base of the system

$$
\sigma^{\prime}=\rho g H-\left(\rho g H-\sigma_{0}^{\prime}\right) \mathrm{e}^{-\frac{3 C_{v} A}{d^{2} Q} L},
$$

where $\rho$ is density, $g$ is the acceleration of gravity, $Q=V / A$ is the volume flowrate and $A$ is the crosssectional area. Given a tailings production rate $Q=1 \mathrm{~m}^{3} / \mathrm{s}$, tailings density $\rho=1200 \mathrm{~kg} / \mathrm{m}^{3}$, initial effective stress $\sigma_{0}^{\prime}=0.1 \mathrm{kPa}$, pond / tower height $H=50 \mathrm{~m}$, drain height $L=10 \mathrm{~m}$, drain spacing $d=0.10 \mathrm{~m}$, consolidation coefficient $C_{v}=10^{-9} \mathrm{~m}^{2} / \mathrm{s}[22]$ and desired effective stress $\sigma^{\prime}=5 \mathrm{kPa}$ [6,23], equation (22) gives the pond footprint $A=\left(d^{2} Q / 3 C_{v} L\right) \ln \left[\left(\rho g H-\sigma_{0}^{\prime}\right) /\left(\rho g H-\sigma^{\prime}\right)\right]=2800 \mathrm{~m}^{2}$. For a larger height $(H=100 \mathrm{~m}, L=20 \mathrm{~m})$ and smaller drain spacing $(d=0.05 \mathrm{~m})$, the footprint reduces to $170 \mathrm{~m}^{2}$. This may be compared to current tailings ponds, which are up to several square kilometres in size [7].

\subsection{Discussion}

A challenge in the design of the system will be to ensure an approximate slip boundary condition is maintained at the drain surfaces. In the intestines this is achieved via a thin lubricating mucus film [10]. This film could potentially be mimicked by using a lubricating fluid similar to drilling muds [24]. The design of the drains will also be important; in contrast to the deformable PVC used in wick drains, the drains in figure 4 must be solid. One possibility is a stainless steel wedge-wire drain, either bare or covered with a sliding cloth filter. Alternatively smooth porous stone slabs, or concrete slabs or tubes, could be used as the drains. A feedback system at the base could be used to monitor the effective stress of the consolidated soil exiting the system [25].

An advantage of the proposed design is that the tailings mixture can be piped directly into the system (figure 4) avoiding the detrimental segregation that occurs on the beach area of large tailings ponds $[21,26]$. The smaller design may also allow the consolidation system to be placed near to the extraction plant; in this case heat from the tailings slurry can be maintained within the system, with the recovered hot water reused, rather than dissipating as the slurry is piped to remote tailings ponds. At sufficiently high temperatures the reduced viscosity of residual bitumen 
within the tailings slurry may allow some of the oil to pass into the vertical drains along with the water, potentially recovering valuable bitumen that is currently stored within the tailings ponds.

While there will doubtless be additional engineering challenges involved, it is hoped the simple model developed here will provide a framework for estimating the basic dimensions of the system. In future work a more realistic model of the rheology of the consolidating mixture could be developed, with no-slip or partial-slip conditions at the drain boundaries; the model could also be generalized by allowing the permeability and consolidation coefficients to depend on the void fraction $[7,10-12,27-30]$.

\section{Conclusions}

A model has been developed of the unidirectional consolidation of a clay soil or colloidal suspension between vertical drains. The system draws inspiration from a similar consolidation process that occurs in the large intestine. Assuming slip boundary conditions at the drain surfaces and using an equal-strain approximation, an expression for the steady-state effective stress profile between the drains has been obtained. A potential application of the method to the consolidation of mine tailings has been described.

\section{Acknowledgements}

This work was made possible by the love and merciful kindness of Jesus, Lord of heaven and earth and Saviour of all who believe. Believe on the Lord Jesus Christ and thou shalt be saved, and thy house. Acts 16:31. The heaven, even the heavens, are the LORD's; But the earth He has given to the children of men. Psalm 115:16

\section{References}

[1] A. T. Jakubick, G. McKenna, and A. M. Robertson. Stabilisation of tailings deposits: International experience. In Mining and the Environment III, pages 1-9, Sudbury, Ontario, 2003.

[2] C. Wang, D. Harbottle, Q. Liu, and Z. Xu. Current state of fine mineral tailings treatment: A critical review on theory and practice. Minerals Engineering, 58, 113-131, 2014.

[3] C. Roche, K. Thygesen, and E. Baker. Tailings storage: Safety is no accident. A UNEP rapid response assessment. Technical Report MSU-CSE-06-2, United Nations Environment Programme and GRID-Arendal, Nairobi and Arendal, 2017.

[4] R. Ifill, N. Beier, C. Zhang, and D. Sego. Crossflow filtration: An option towards compliance with directive 074. Geotechnical News, 28, 30-33, 2010.

[5] Chris Powter, Kevin Biggar, M.J. Silva, Gordon Mckenna, and Elisa Scordo. Review of oil sands tailings technology options. In Tailings and Mine Waste'10 - Proceedings of the 14th International Conference on Tailings and Mine Waste, pages 381-391, 2011.

[6] OSTC. Technical Guide for Fluid Fine Tailings Management. Technical report, Oil Sands Tailings Consortium, Calgary, Alberta, 2012.

[7] S. Jeeravipoolvarn, W. Miller, D. Scott, L. Kabwe, and W. Wilson. Modeling effect of bitumen extraction processes on oil sands tailings ponds. Journal of Civil Engineering and Architecture, 11, 48-59, 2017.

[8] H. Rourke and D. Hockley. Assessing oil sands tailings consolidation parameters relative to long-term reclamation. In Proceedings Tailings and Mine Waste 2018, pages 127-138, Keystone, Colorado, USA, 2018. 
[9] Roger G. Lentle, Patrick W.M. Janssen, and Ian D. Hume. The roles of filtration and expression in the processing of digesta with high solid phase content. Comparative Biochemistry and Physiology Part A: Molecular \&5 Integrative Physiology, 154, 1-9, 2009.

[10] Patricia J. Yang, Morgan LaMarca, Candice Kaminski, Daniel I. Chu, and David L. Hu. Hydrodynamics of defecation. Soft Matter, 13, 4960-4970, 2017.

[11] Duncan R. Hewitt, Daniel T. Paterson, Neil J. Balmforth, and D. Mark Martinez. Dewatering of fibre suspensions by pressure filtration. Physics of Fluids, 28, 063304, 2016.

[12] Duncan R. Hewitt, Japinder S. Nijjer, M. Grae Worster, and Jerome A. Neufeld. Flow-induced compaction of a deformable porous medium. Phys. Rev. E, 93, 023116, 2016.

[13] J. Bear. Dynamics of Fluids in Porous Media. Elsevier, NY, 1972.

[14] Arnold Verruijt. An Introduction to Soil Dynamics. Springer, Dordrecht, 2010.

[15] R. B. Bird, W. E. Stuart, and E. N. Lightfoot. Transport Phenomena Second Edition. Wiley, N.Y., 2002.

[16] H. Wang. Theory of Linear Poroelasticity. Princeton University Press, USA, 2000.

[17] S. Hansbo. Consolidation of fine-grained soils by prefabricated drains. In Proceedings of 10th International Conference on Soil Mechanics and Foundation Engineering, volume 3, pages 677-682, Stockholm, Sweden, 1981.

[18] B. Indraratna and I. W. Redana. Plane-strain modeling of smear effects associated with vertical drains. Journal of Geotechnical and Geoenvironmental Engineering, 123, 474-478, 1997.

[19] Faisal Haji Ali. The flow behaviour of deformed prefabricated vertical drains. Geotextiles and Geomembranes, 10, 235-248, 1991.

[20] Tailings Ponds 101, Oil Sands Magazine. https://www.oilsandsmagazine.com/technical/ mining/tailings-ponds.

[21] Chris Powter, Kevin W. Biggar, Gordon Mckenna, Elisa Scordo, and BGC Engineering. Oil Sands Tailings Technology Review. Technical report, University of Alberta, School of Energy and the Environment, OSRIN, Report No. TR-1, 2010.

[22] S. Proskin, D. Sego, and M. Alostaz. Freeze-thaw and consolidation tests on Suncor mature fine tailings (MFT). Cold Regions Science and Technology, 63, 110-120, 2010.

[23] Nicholas Beier, Ward Wilson, Adedeji Dunmola, and David Sego. Impact of flocculation-based dewatering on the shear strength of oil sands fine tailings. Canadian Geotechnical Journal, 50, 1001-1007, 2013.

[24] Johannes Fink. Petroleum Engineer's Guide to Oil Field Chemicals and Fluids (Second Edition). Gulf Professional Publishing, Boston, 2015.

[25] Chee Keong Tan, Ridwan Setiawan, Jie Bao, and Götz Bickert. Studies on parameter estimation and model predictive control of paste thickeners. Journal of Process Control, 28, $1-8,2015$.

[26] J. Yang. Computational Fluid Dynamics Modeling of Deposition of Oil Sand Slurry into Mature Fine Tailings. PhD thesis, University of Alberta, 2009.

[27] W. B. Russel, D. A. Seville, and W. R. Schowalter. Colloidal Dispersions. Cambridge University Press, U.K., 1989.

[28] K. A. Landman, C. Sirakoff, and L. R. White. Dewatering of flocculated suspensions by pressure filtration. Physics of Fluids A: Fluid Dynamics, 3, 1495-1509, 1991. 
[29] S. S. L. Peppin, J. A. W. Elliott, and M. G. Worster. Solidification of colloidal suspensions. J. Fluid Mech., 554, 147-166, 2006.

[30] S. S. L. Peppin. Dynamic colloidal membranes. EngrXiv, DOI:10.31224/osf.io/9sqhb, 2021. 